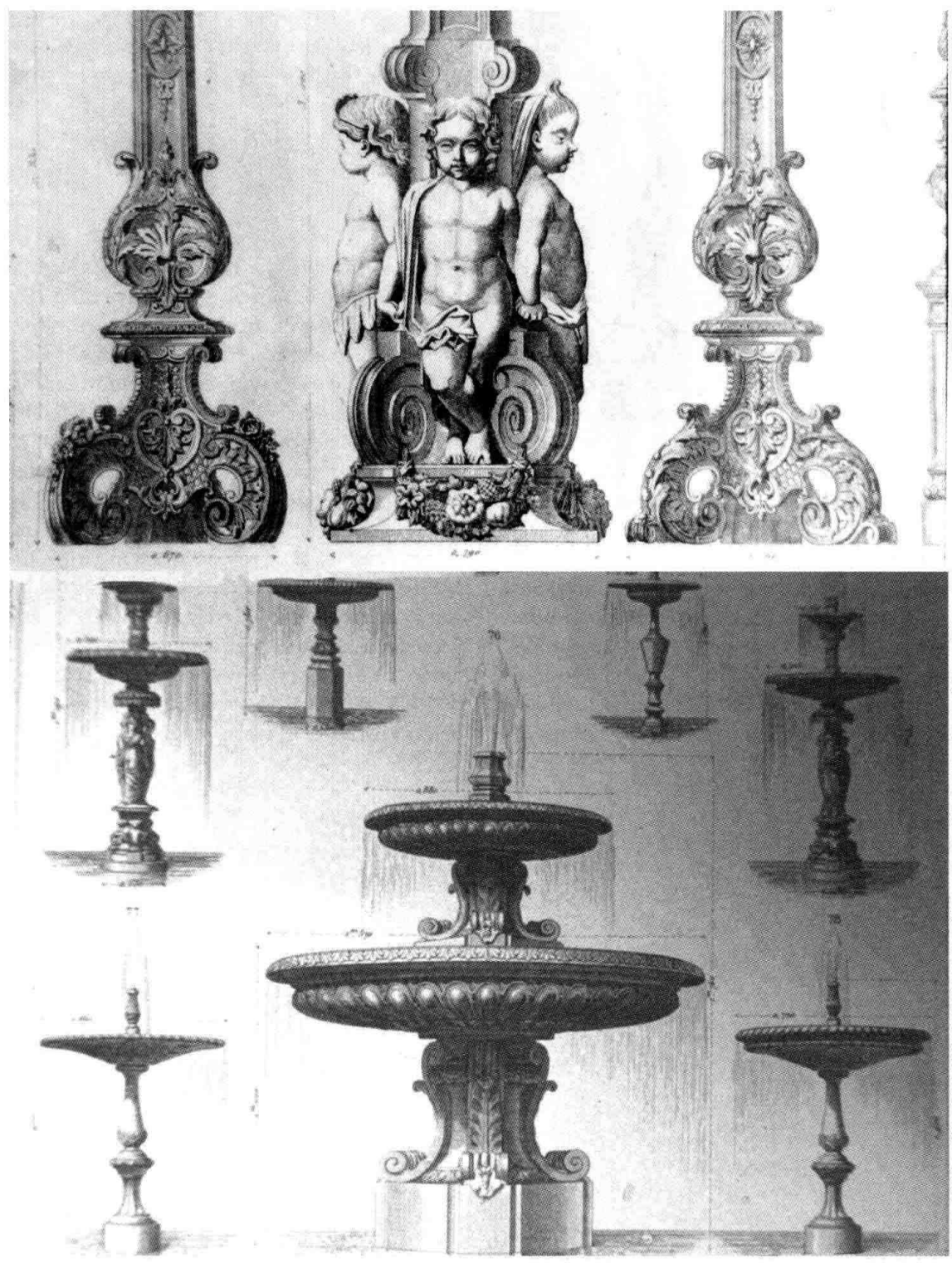




\section{Alejandro Monsiváis Carrillo}

Doctor en Ciencias Sociales. Profesor-investigador en el Instituto Mora adscrito al área de Sociología Política y Económica. Sus temas de interés son la construcción de ciudadanía, la política deliberativa y la rendición de cuentas en las democracias en consolidación.

\section{Resumen}

La deliberación pública pretende sentar una base sólida para el fortalecimiento y la profundización de la democracia. Sin embargo, desde una perspectiva posestructuralista en teoría política, se piensa que esta idea, debido a sus supuestos normativos, es inconveniente para tal propósito. Este artículo discute las perspectivas deliberativas y posestructuralistas en torno a la democracia. Por un lado, se muestra que el enfoque posestructuralista, a pesar de sus aportaciones, carece de una formulación precisa acerca de cómo construir instituciones y prácticas democráticas. Por otra parte, se discuten ciertas aproximaciones deliberativas a la democracia que proporcionan tal formulación. En una de ellas se ilustra la relevancia de la deliberación para entender los procesos de democratización en América Latina.

Palabras clave:

Democracia, deliberación pública, antagonismo, pluralismo, agonismo.

\section{Abstract}

Public deliberation attempted to establish a solid basis for reinforcing and expanding democracy. However, from a post-structuralist perspective in political theory, it is thought that this idea, due to its normative assumptions, is unsuitable for this purpose. This article discusses the deliberative and post-structuralist perspectives regarding democracy. On the one hand, it shows that, despite its contributions, the post-structuralist approach lacks a precise formulation of how to construct institutions and democratic practices. On the other hand, the article discusses certain deliberative approaches to democracy that provide this formulation. One of them illustrates the importance of deliberation in understanding the processes of democratization in Latin America.

\section{Key words:}

Democracy, public deliberation, antagonism, pluralism, agonism.

Fecha de recepción:

febrero de 2004

Fecha de aceptación:

noviembre de 2004 


\title{
Deliberación pública, pluralismo agonístico y democracia. Reafirmación de la democracia deliberativa ante la crítica posestructuralista
}

\author{
Alejandro Monsiváis Carrillo
}

$\mathrm{D}$ urante la última década del siglo $\mathrm{xx}$, el principio de deliberación pública adquirió centralidad en la teoría de la democracia. La deliberación pública, tal como es concebida por distintos partidarios de esta perspectiva, no solamente tiene la intención de ofrecer un recuento más sustantivo de los procesos democráticos, sino que se asume como la dimensión esencial de la democracia misma. ${ }^{1}$ Establecer estándares de legitimación política sustantivos y robustos responde al propósito de fortalecer la viabilidad de los ideales democráticos en la sociedad contemporánea. La idea de deliberación pública intenta combatir el escepticismo que producen fenómenos

${ }^{1}$ Al respecto, véase esta afirmación: "Actualmente, la esencia misma de la democracia se identifica ampliamente con la deliberación, y no con las votaciones, la agregación de intereses, los derechos constitucionales o, inclusive, el autogobierno." Dryzek, Deliberative, 2000, p. 1 (la traducción es mía). En el mismo sentido, Habermas dice lo siguiente: "Según el resultado de nuestras consideraciones relativas a teoría del derecho, el procedimiento que representa la política deliberativa constituye la pieza nuclear del proceso democrático." Habermas, Facticidad, 2001, p. 372. En la primera sección de este trabajo se hace un breve bosquejo de las razones por las que es posible darle este estatus a la deliberación pública. como el cinismo y la acción instrumental, la exclusión y la desigualdad, el pluralismo y los desacuerdos, o la complejidad y la diferenciación sistémicas que, en conjunto, están presentes en las sociedades contemporáneas. La idea de deliberación pública se convierte en un aspecto esencial de los procesos democráticos porque establece un nuevo estándar de legitimidad política. La deliberación pública designa el proceso ideal por medio del cual se legitiman las decisiones políticas cuando están basadas en un entendimiento racional que es producto de la participación, en condiciones de igualdad y libertad, de todos los actores involucrados por dicha decisión.

La concepción deliberativa de la democracia, al igual que ha ganado adeptos, ha sido objeto de severas críticas. En este artículo me interesa discutir una de las vertientes del pensamiento político contemporáneo que se muestra particularmente crítico con los supuestos y las expectativas de la democracia deliberativa. Esta vertiente ha producido diversas intervenciones teóricas en torno a la concepción de lo político y la teoría de la democracia desde un bagaje conceptual formado en las -si cabe agruparlas bajo estos términos- tradiciones del pensamiento 
posestructuralista y deconstructivo. ${ }^{2}$ Desde una concepción no fundacional de lo político y lo social, los planteamientos que se hacen en esta vertiente señalan que las ambiciones del ideal deliberativo son simplemente inadecuadas para contribuir a profundizar la democracia. Desde este punto de vista, colocar las expectativas de igualdad, que trae consigo el ideal democrático, en formas de justificación política basadas en un consenso racional, restringe innecesariamente el campo de acciones políticas que se consideran legítimas. Por el contrario, el ideal democrático - dice el argumento- debe ser capaz de dar cuenta de las relaciones de poder, antagónicas, que son constitutivas de lo político, si aspira a imaginar una organización política donde tengan plena cabida el pluralismo y la diferencia cultural.

Este trabajo pretende examinar las concepciones deliberativas y posestructurales/deconstructivas de la democracia. El propósito es argumentar que el pluralismo radical, que encuentra en la lógica democrática un orden político apropiado para organizar la indeterminación del poder, no puede prescindir de un planteamiento comunicativo, flexible y complejo si aspira a cumplir los ideales del proyecto democrático. El punto consiste en no perder de vista que el adversario de tal proyecto no es el ideal de la deliberación pública, sino una concepción del proceso

${ }^{2}$ Estas categorías pretenden hacer referencia a la obra de autores tan disímiles entre sí como Michel Foucault, Jacques Derrida, Gilles Deleuze y Jacques Lacan, entre otros, y a su correspondiente influencia en el pensamiento "posmoderno". Enlistar los movimientos teóricos, y los autores, que han transformado el pensamiento filosófico-político contemporáneo, está fuera de los objetivos de este trabajo. deliberativo que restringe el desarrollo de la autenticidad democrática. Esto supone dar un voto - mejor dicho, un argumento- a favor de una interpretación deliberativa de la democracia, ante la perspectiva posestructuralista. ${ }^{3}$ Para dar cuenta de estos argumentos, la primera sección de este trabajo expone la concepción básica de la democracia deliberativa y las críticas provenientes del campo posestructuralista. En segundo lugar, se desarrolla el modelo del "pluralismo agonístico", de Chantal Mouffe, ${ }^{4}$ para asentar cómo se concibe la democracia desde la perspectiva posestructural/deconstructiva. El tercer apartado señala las limitaciones a las que conduce este modelo, cuando se trata de conceptuar los procesos de construcción de instituciones y prácticas democráticas. La parte final del texto retorna a los desarrollos críticos de la deliberación pública. El objetivo es mostrar que desde estas perspectivas se pueden responder las objeciones que los posestructuralistas hacen a la concepción básica de la deliberación pública; y además, que los desarrollos de esta vertiente deliberativa dan respuestas

${ }^{3}$ En este ensayo no pretendo hacer una descripción exhaustiva de la -ya extensa y en rápida expansión- bibliografía acerca de la democracia deliberativa. En español se ha publicado un dossier en el tema que puede ser una introducción útil para el lector interesado. Véase Metapolítica, 2000. Algunas compilaciones que son pertinentes para conocer las principales líneas del debate son Bohman, Deliberative, 1999; Elster, Democracia, 2001, y Fishkin y Laslett, Debating, 2003. En Kymlicka, Contemporary, 2002, pp. 284-326, además de un listado de lecturas sugeridas se proporcionan referencias electrónicas para su consulta.

${ }^{4}$ Véanse Mouffe, "Democratic", 1992; Retorno, 1999, y Democratic, 2000; véase también Laclau y Mouffe, Hegemony, 1985. 
más claras acerca de cómo promover la autenticidad democrática. Con ese fin, la cuarta sección discute la propuesta de la democracia discursiva de John Dryzek, y la concepción de los "públicos participativos" de Leonardo Avritzer. Este último constituye, en específico, un replanteamiento de las teorías de la democracia en América Latina.

\section{DELIBERACIÓN, JUSTIFICACIÓN POLÍTICA Y DEMOCRACIA}

La revitalización que ha tenido la filosofía política en las últimas décadas ha estado centrada en fundamentar racionalmente las condiciones en las que es posible pensar cómo construir sociedades justas, sin menoscabar las libertades ni la equidad entre los individuos. La democracia, para muchos, es el modelo de ordenamiento político capaz de llevar a cabo la tarea de construir una sociedad más justa. Sin embargo, aun entre quienes comparten esta idea, existe desacuerdo en torno a cómo debe ser concebido un proyecto democrático que responda a este imperativo. Un elemento que sirve para identificar distintas posiciones en el debate en torno a la democracia es la idea de deliberación pública. Para los partidarios de la deliberación, la expansión de las esferas de la vida pública, en la que se toman decisiones vinculantes con base en el intercambio inclusivo y equitativo de razones, es el eje de un proyecto, si no emancipatorio, por lo menos ordenador de la sociedad en términos de justicia política. Otras posiciones se muestran escépticas ante la capacidad de la deliberación para lograr dicho propósito. En esta sección voy a referirme a la idea básica de la democracia deliberativa y a las críticas que, desde una posición posestructural y deconstructiva, se hacen a dicha formulación.

\section{Democracia deliberativa: la concepción básica}

La democracia deliberativa se entiende como la institucionalización de un ideal de justificación política. Éste establece que el ejercicio colectivo del poder debe estar basado en el intercambio de razones entre ciudadanos libres e iguales. Para asentar claramente cómo se establece esta formulación, es necesario citar en extenso la definición que hace Joshua Cohen:

The deliberative conception of democracy is organized around an ideal of political justification. According to this ideal, justification of the exercise of collective political power is to proceed on the basis of a free public reasoning among equals. A deliberative democracy institutionalizes this ideal. Not simply a form of politics, democracy, on the deliberative view, is a framework of social and institutional conditions that facilitates free discussion among equal citizens [...] and ties the authorization to exercise public power (and the exercise itself) to such discussion -by establishing a framework ensuring the responsiveness and accountability of political power to it through regular competitive elections, conditions of publicity, legislative oversight, and so on. ${ }^{5}$

5 "La concepción deliberativa de la democracia se organiza en torno a un ideal de justificación política. De acuerdo con este ideal, la justificación del ejercicio del poder político debe tener su base en un proceso de razonamiento libre y público entre iguales. Una de- 
El ideal deliberativo se opone a una concepción agregativa del proceso democrático. El modelo agregativo supone que la preservación del procedimiento democrático en las sociedades complejas ya no tiene que estar basado en la participación directa de todos los ciudadanos en los asuntos de la polis, sino en la suma de las preferencias individuales para la elección de representantes y políticas públicas. ${ }^{6}$ Esta concepción asume que los procesos políticos funcionan como un mercado donde partidos políticos, actores y ciudadanos intercambian ofertas y votos, de acuerdo con el mejor postor. Este modelo privilegia una forma de relación instrumental y pragmática con los procesos políticos. Los ciudadanos, vistos desde este enfoque, para influir en la política pública no requieren de pasar por el proceso de deliberación pública, ya que la transmisión de sus preferencias se realiza de manera individualizada y secreta, a través del voto.

\footnotetext{
mocracia deliberativa institucionaliza este ideal. En la visión deliberativa, la democracia no es simplemente una forma de hacer política; es un marco de condiciones institucionales y sociales que facilita la libre discusión entre ciudadanos iguales [...] [y] que vincula la autorización de ejercer el poder público ly el ejercicio mismo de ese poder] a tal discusión -al establecer un marco que asegura la rendición de cuentas del poder político a través de elecciones competitivas y regulares, condiciones de publicidad, supervisión legislativa y demás" (la traducción es mía). Cohen, "Procedure", 2003, p. 21.

${ }^{6}$ Esta concepción del proceso democrático fue desarrollada originalmente en los trabajos de Schumpeter, Capitalism, 1947, y Downs, Economic, 1957. Una crítica de las teorías democráticas de corte minimalista, que excluyen del proceso político los aspectos normativos y deliberativos, se encuentra en Elster, "Market", 2003.
}

Contra esta versión minimalista e instrumental del proceso democrático, Cohen defiende la alternativa de la democracia deliberativa, la cual permite ir más allá de la idea procedimental clel proceso político, al ser capaz de reintroducir el ideal del bien común en el proceso democrático. Más aún, Cohen afirma que la idea de deliberación va ligada también con la preservación de las libertades de los "antiguos" y de los "modernos". ${ }^{7} \mathrm{El}$ procedimiento deliberativo implica la participación de los ciudadanos de la asociación política en la toma de decisiones vinculantes, de esta manera es coherente con las libertades (de participación) de los antiguos. Al mismo tiempo, el dar un trato de equidad a ciudadanos libres en el procedimiento deliberativo va acompañado de la necesidad de preservar las libertades de los "modernos", defendidas por la tradición liberal: libertad de expresión, culto, asociación, etc. El bien común se introduce cuando el producto del proceso político supone un acuerdo racional acerca de lo que es adecuado para todos los miembros de la comunidad política.

La concepción deliberativa de la democracia tiene su origen en los desarrollos normativos elaborados desde dos tradiciones del pensamiento político: el liberalismo político y la teoría crítica. El replanteamiento de la teoría de la justicia de Rawls, en términos de un liberalismo político, es una de las fuentes de la concepción deliberativa de la democracia. ${ }^{8}$ Rawls, al reconocer el "hecho del pluralismo" en las sociedades contemporáneas, renuncia a ver su teoría de la justicia

${ }^{7}$ Véanse Cohen, "Procedure", 2003, y "Democracia", 2001.

${ }^{8}$ Rawls, Political, 1996. 
como una "doctrina comprensiva", cuya función sería regular tanto las instituciones como la moral de una sociedad bien ordenada. En cambio, propone que los principios de dicha teoría de la justicia deben ser entendidos solamente como el producto de un "consenso traslapado" en torno las instituciones políticas de la sociedad. El liberalismo político funciona como una suerte de elemento articulador, imparcial, de una cultura política pública, en la que se "traslapan" "doctrinas comprensivas" irreconciliables entre sí. Una concepción política de la justicia, entonces, consiste en una serie de principios que pretenden sentar las bases de un ordenamiento de las instituciones políticas, de manera que garanticen la libertad y la equidad de todos los miembros de la sociedad.

Una sociedad "bien ordenada" en su estructura política se caracteriza, además, porque el método por medio del cual sus miembros resuelven cuestiones acerca de la estructura básica de su sociedad y de justicia fundamental es el de la "razón pública". Este principio implica que los ciudadanos deben conducir sus discusiones dentro del marco de lo que cada uno considera una concepción política de la justicia (y no una concepción "comprensiva" de la misma), la cual debe estar basada en valores que los otros deben estar dispuestos a suscribir racionalmente. ${ }^{9} \mathrm{La}$ concepción de la "razón pública" de Rawls ha causado controversias. Dos afirmaciones que dan lugar a diversas críticas: Rawls es enfático al señalar que la razón pública tiene por objeto resolver, exclusivamente, cuestiones de diseño constitucional y de la estructura básica de la socie-

${ }^{9}$ Ibid., p. 226. dad $;^{10}$ y que la razón pública -la apelación a los valores y principios que otros razonablemente estarían dispuestos a aceptar-contrariamente a las razones no públicas, de las que hay muchos tipos, es una sola. ${ }^{11}$

Otra vertiente que ha animado los debates en torno a la concepción deliberativa de la democracia proviene de la teoría crítica; más específicamente, de la obra de Jürgen Habermas. La teoría de la democracia de Habermas, desarrollada en términos de teoría del discurso, consiste en la reconciliación de los principios que fundamentan el Estado de derecho con el principio de soberanía popular que caracteriza a la democracia. ${ }^{12}$ Este planteamiento procede de las implicaciones normativas de la teoría de la comunicación de este autor. La comunicación presupone una forma de racionalidad que no se limita a buscar arreglos eficientes respecto a medios y fines, sino que da forma a un ideal de entendimiento basado en la fuerza del mejor argumento. ${ }^{13}$ Para Habermas, el potencial emancipatorio de la racionalidad comunicativa, que se traduciría en el desarrollo de formas de vida reflexivas y equitativas en el mundo de la vida, ha sido opacado por la penetración de una racionalidad instrumental, proveniente de las funciones de integración sistémica representadas por el poder económico y por el poder administrativo del Estado. ${ }^{1 / 1}$

La política deliberativa representa un esfuerzo para pensar la introducción de

${ }^{10} \mathrm{Ibid.}$., p. 214.

"Ibid., p. 220.

12 Véanse Habermas, "Tres", 1999, y Facticidad, 2001.

${ }^{13}$ Habermas, Teoria, 1999, vol. I.

${ }^{14}$ Ibid., vol. Ir. 


\section{SECUENCIG}
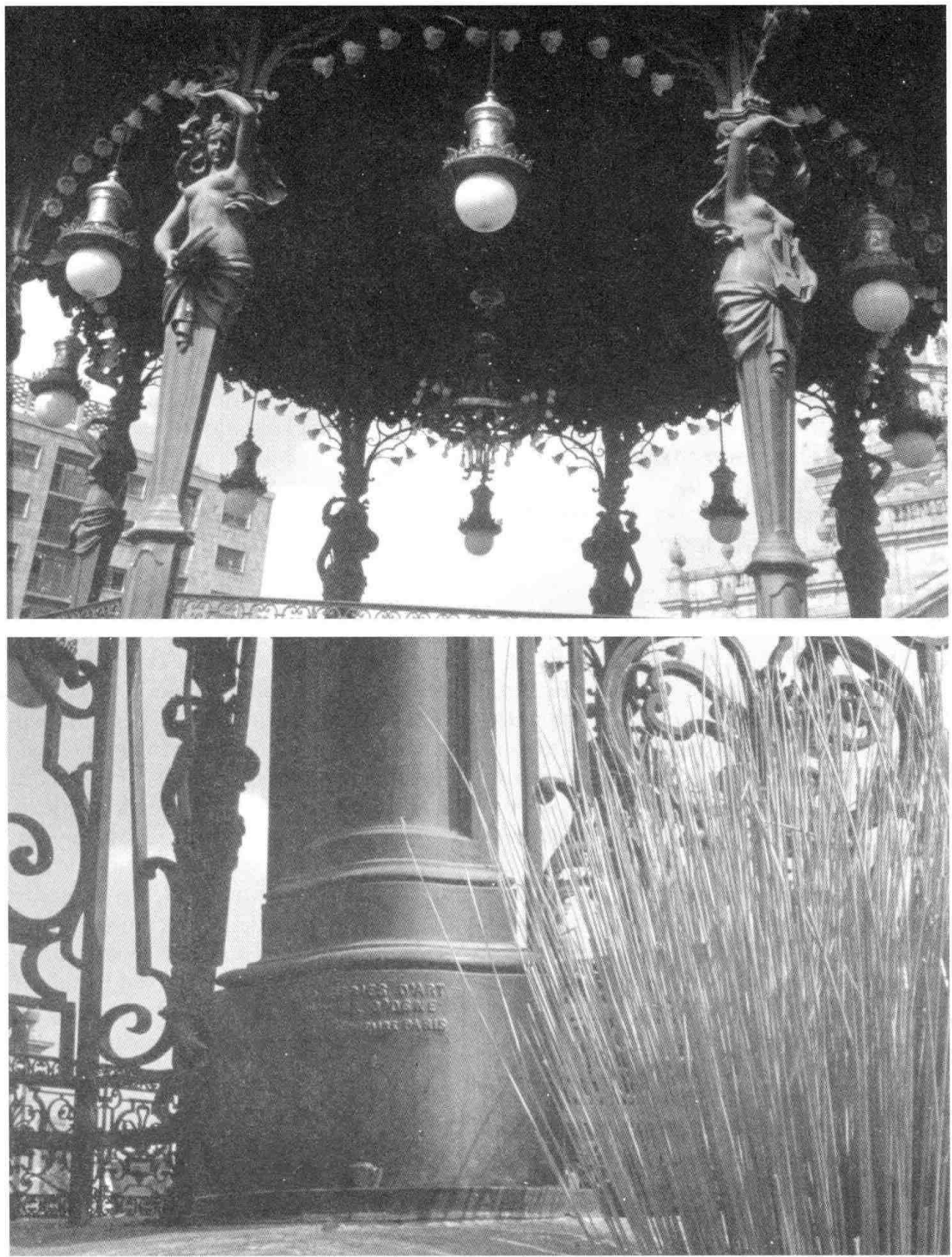
los ideales normativos de la racionalidad comunicativa (la ética del discurso) en las instituciones reguladoras de la sociedad contemporánea. Esbozada de manera muy sucinta, esta teoría vincula la legitimidad del derecho en la sociedad contemporánea con un proceso comunicativo de formación de la voluntad y la decisión políticas. Para Habermas, la diferenciación sistémica de las sociedades actuales tiene como único medio efectivo de integración compleja al sistema representado por el derecho. Éste se convierte en la estructura integradora de la "comunidad societal", en la medida en que traduce el poder comunicativo generado en la esfera pública y, por medio de procedimientos democráticos, lo convierte en un poder legítimo, ejercido a través de las estructuras coercitivas y administrativas del Estado. En este modelo, la función de la política deliberativa es darle forma a la voluntad popular y convertirla en leyes. Los procedimientos que permiten transformar la voluntad popular en disposiciones vinculantes están fundamentados en los derechos y libertades individuales; en este sentido, los derechos defendidos por el liberalismo político son complementarios y cooriginarios con la soberanía popular. El modelo de política deliberativa habermasiano implica que los acuerdos deben estar basados en un consenso donde los participantes comparten una decisión por las mismas razones. El estándar para valorar un producto legítimo de un proceso de la deliberación pública es un acuerdo consensuado y unánime. Esto se debe a que el proceso de deliberación se concibe como el intercambio razonado de argumentos, y a que el proceso es entendido como la obtención de un consenso donde todos los partici- pantes llegan a estar de acuerdo por las mismas razones. ${ }^{15}$

\section{Señalamientos críticos al ideal de deliberación pública}

Las objeciones que se hacen a la concepción deliberativa de la democracia se dirigen contra las consecuencias de los planteamientos de Rawls y Habermas. Entre ellas, cabe destacar dos que son particularmente importantes. En primer lugar, se dice que el giro deliberativo en la teoría política habría buscado la justificación normativa de la articulación entre el liberalismo y la democracia: la idea de deliberación pública es una forma de razón práctica que articula la idea de la preservación de los derechos individuales con el procedimiento para la toma de decisiones colectivas con carácter vinculante. En segunda instancia, se señala que los ideales de unanimidad y razón pública que sustentan los principios de legitimidad deliberativa son poco eficientes para la toma de decisiones en el mundo real y sobre

${ }^{15}$ Este punto es compartido por Joshua Cohen, quien establece, en una de las primeras formulaciones de los principios regulativos de la democracia deliberativa, que el ideal de la deliberación es el arribo a una situación de consenso: "Ideal deliberation aims to arrive at the rationally motivated consensus - to find reasons that are persuasive to all who are committed to acting on the results of a free and reasoned assessment of alternatives by equals". Cohen, "Deliberation", 2002, p. 93. ("La deliberación ideal espera arribar a un consenso racionalmente motivado -es decir, espera encontrar razones que sean persuasivas para todos los que se han comprometido a acatar los resultados de un intercambio libre y razonado de alternativas entre ciudadanos iguales" (la traducción es mía). 
todo son demasiado restringidos para dar cuenta de la pluralidad de puntos de vista $y$ formas de vida en el mundo contemporáneo.

Desde una perspectiva informada por los debates posestructurales y antiesencialistas no sólo se cuestiona la capacidad de la política deliberativa de Habermas y la noción del "consenso traslapado" de Rawls para enfrentar los dilemas del pluralismo y el desacuerdo en las sociedades contemporáneas, sino que se piensa que la idea de deliberación dimanada de dichas teorías pone en peligro el ideal mismo de la democracia. Para Chantal Mouffe, representante de la vertiente posestructural de la teoría política, la democracia deliberativa incurre en el error de olvidar que la articulación entre las instituciones liberales y los procedimientos democráticos es un producto histórico contingente. ${ }^{16}$ Para esta autora, la perdurabilidad de dicho arreglo no depende de ninguna lógica trascendental, sino del devenir del proceso histórico mismo. Por ello, naturalizar esa articulación por medio de la filosofía política implica suponer que la permanencia de las instituciones democráticas depende de su justificación racional, cuando nada hay que garantice tal supuesto. Al contrario, de lo que se trata es de encarar la tarea de profundizar el proyecto democrático, asumiendo que su continuidad depende de los esfuerzos de los sujetos identificados con los valores democráticos.

Mouffe es enfática en señalar que ni la idea de la política deliberativa de $\mathrm{Ha}$ bermas ni el liberalismo político de Rawls son fundamentos adecuados y suficientes para asumir el reto de profundizar la de-

${ }^{16}$ Mouffe, Democratic, 2000, p. 94. mocracia. De hecho, considera bastante perniciosa la influencia del pensamiento liberal en la teoría democrática. Esta autora considera que el liberalismo es una teoría política sin política, pues esta tradición no es capaz de reconocer la dimensión polémica, disruptiva, de lo político en la confirmación de razones públicas ni en el sistema de inclusiones/ exclusiones en los que se basa toda delimitación de una comunidad política. De esta manera, la apropiación liberal de la idea de deliberación pública supone la creación de un escenario de consenso basado en la exclusión de la posibilidad de disenso. En esta dirección apunta la observación de Mouffe de que el "pluralismo razonable" no puede solventar los conflictos de principio entre mundos de vida distintos por medio de la apelación a una sola "razón pública", cuando lo que puede ser objeto de disputa son los contenidos de esa misma razón. Por lo tanto, los aspectos conflictivos de las relaciones sociales -expresando razones no públicas-, al quedar excluidas de la posibilidad de ingresar en el escenario legítimo de deliberación pública, antes que fortalecer el orden democrático representan amenazas para su continuidad.

Mouffe piensa que la visión racionalista y normativa de la legitimidad política del ideal deliberativo incurre en el error de despolitizar lo político, al ser incapaz de resolver satisfactoriamente la dimensión polémica y antagónica de la constitución de las identidades y los ordenamientos sociales que se pretenden regular por medio de la apelación a principios de argumentación y consenso. El ideal de deliberación, cuando aspira a lograr un acuerdo unánime y consensual en el intercambio de razones, no puede ser 
considerado un fundamento adecuado ni para garantizar la permanencia de las instituciones democráticas ni para profundizar la implantación de las prácticas y valores de este ordenamiento político. Para autores como Mouffe, lo que está en juego no es reemplazar una visión estratégica de la democracia por una basada en la comunicación o la deliberación. Llevar a cabo la radicalización del proyecto democrático conlleva asumir que su continuidad depende de los esfuerzos de los sujetos identificados con los valores democráticos. De lo que se trata, antes que de una justificación racional, es de hacer disponibles las prácticas que hagan efectivos los ideales democráticos:

We can realize that what is really at stake in the allegiance to democratic institutions is the constitution of an ensemble of practices that make possible the creation of democratic citizens. This is not a matter of rational justification but of availability of democratic forms of individuality and subjectivity. ${ }^{17}$

Antes de preguntar qué pistas proporciona Mouffe para hacer disponibles las formas democráticas de subjetividad, es necesario explorar su modelo del "pluralismo agonístico".

17 "Podemos darnos cuenta de que lo que realmente está en juego en la lealtad a las instituciones democráticas es la constitución de un conjunto de prácticas que hagan posible la creación de ciudadanos democráticos. No es una cuestión de justificación racional, sino de la disponibilidad de formas democráticas de individualidad y subjetividad" (la traducción es mía). Ibid., p. 95.

\section{DEMOCRACIA RADICAL Y PLURALISMO AGONÍSTICO}

Las discusiones en torno a la democracia deliberativa parecen estar separadas de los planteamientos provenientes de discusiones posestructurales y deconstructivas por una profunda brecha conceptual. Aletta J. Norval señala que los teóricos de la democracia difieren marcadamente al menos en tres puntos. ${ }^{18} \mathrm{El}$ primero de esos puntos se refiere a la finalidad de la actividad democrática. Para los partidarios de la deliberación, la meta es alcanzar un consenso racional; los demócratas radicales de tradición posestructural ponen énfasis en el potencial disruptivo y dislocatorio de la democracia. En segundo lugar, mientras que la concepción deliberativa de la democracia está inspirada en un modelo de diálogo sin constricciones, los posestructuralistas consideran que las relaciones de poder son constitutivas de las relaciones democráticas. Finalmente, contrario a lo que pretenden sus contrapartes deliberativos, aquéllos no intentan especificar precondiciones normativas para el discurso democrático. Estas críticas son válidas para la concepción estrictamente habermasiana de la política deliberativa, pero no necesariamente lo son para todas las propuestas deliberativas. A partir de las diferencias en los puntos indicados, se percibe que la distancia que se abre entre ambas perspectivas no depende meramente de distintas maneras de interpretar los hechos, sino de principios ontológicos incompatibles.

${ }^{18}$ Norval, "Democratic", 2000, pp. 20-21. 
La imposibilidad de la "sociedad" y la democracia radical

El propósito de esta sección es desarrollar los supuestos filosóficos y políticos del modelo del "pluralismo agonístico" de Chantal Mouffe -una de los teóricos políticos que se adscriben a sí mismos en la vertiente posestructural y deconstructiva. El pensamiento político de Mouffe se nutre de un conjunto vasto y complejo de aportaciones provenientes de movimientos teóricos que han cuestionado los distintos fundamentos del pensamiento moderno. ${ }^{19} \mathrm{La}$ impronta posestructural y deconstructiva en el pensamiento de esta autora es evidente en la conceptualización que hace de la "realidad" de la "sociedad". Esta es "imposible", vista desde la teoría (deconstructiva) del discurso, puesto que su existencia misma depende de una negatividad que lo subvierte. ${ }^{20}$ Esto se refiere a que la "realidad" de la sociedad, su "objetividad", carece de un punto de sutura que le permitiría reconciliarse consigo misma, como una entidad completa. El elemento que impide esa reconciliación no es ningún elemento positivo, sino una negatividad, producida por el hecho de

${ }^{19}$ Chantal Mouffe, con formación en el pensamiento de Marx y Gramcsi, reconoce explícitamente la influencia, en su obra, de autores como Claude Lefort, Carl Schmitt, Ludwig Wittgenstein, Michel Foucault y Jacques Derrida, entre otros.

${ }^{20}$ Este planteamiento proviene de la deconstrucción realizada por Laclau y Mouffe (Hegemony, 1985, pp. 105-114) de la noción de discurso. El discurso no designa solamente los elementos linguísticos de la realidad, sino que es constitutivo, por medio de prácticas significantes, de esa misma realidad. Una aplicación de dicho planteamiento en el análisis político se encuentra en Howarth, Norval y Stavrakakis, Discourse, 2000. buscar la estructuración de un sistema inteligible. Dicha negatividad asume una forma positiva en el elemento o agente respecto al cual lo social establece una diferencia. La noción de constitutive outside, acuñada por Derrida, le sirve a Mouffe para designar, precisamente, la necesidad -establecida de forma contingente- de toda identidad de basarse en un elemento externo, disruptivo, que amenaza constantemente su integridad; pero que, al mismo tiempo, es el elemento que la hace posible.

Este argumento está estrechamente vinculado con el significado que adquiere lo político y el replanteamiento del concepto de hegemonía en Laclau y Mouffe. ${ }^{21}$ La imposibilidad de la "sociedad" de constituirse como una unidad positiva implica que no existe una lógica que se autorreproduzca para estructurar cada sociedad. A su vez, esto lleva a la conclusión de que toda representación empírica de lo social es producto de una articulación contingente de elementos. Dicha articulación, instaurada en narrativas, instituciones y prácticas, se considera una articulación hegemónica en la medida en que consigue "crear" e integrar lo social. Los procesos de producción de dicha formación hegemónica son "políticos" en un doble sentido: en la medida en que actualizan y naturalizan relaciones de poder, y en la medida en que son producto de una "decisión" para la cual no hay fundamento ni horizonte preestablecidos. ${ }^{22}$ En otras palabras, la constitución de la sociedad es un efecto correlativo a la intervención de

${ }^{21}$ Laclau y Mouffe, Hegemony, 1.985, pp. 134-145; véase también Laclau, "New", 1990, pp. 28-31.

${ }^{22}$ Véase Laclau, "Deconstrucción", 1998, pp. 109-124. 
lo político en la construcción de una articulación hegemónica.

La idea de la imposibilidad constitutiva de la sociedad, al igual que las nociones de lo político y la hegemonía también están vinculadas con el concepto de antagonismo. Éste, para Laclau y Mouffe, no puede equipararse ni con la contradicción lógica ni con la confrontación de dos fuerzas opuestas. Antagonismo es toda relación de conflicto que se produce cuando una identidad -un agente, una sociedad-se construye y fracasa en su constitución, todo al mismo tiempo. Los antagonismos están ligados a la imposibilidad lógica de una identidad de llegar a ser una objetividad completa; se producen en el momento paradójico en que esa identidad resulta configurada y subvertida simultáneamente. ${ }^{23} \mathrm{La}$ construcción de la identidad de lo social, de igual manera que involucra un proceso hegemónico de articulación de diversos elementos, también requiere de establecer límites que la distingan de lo que ella no es. Esos límites, con los que se definen insiders y outsiders, son efecto de una operación política, pues su establecimiento es arbitrario: carecen de un sentido ontológico preexistente. La tensión que se instaura con esa división es la tensión que define los antagonismos, $y$ no es producto de un conflicto contingente entre dos identidades, sino de la necesidad misma de una de ellas de constituirse por oposición a la otra.

Estas puntualizaciones permiten comprender mejor la concepción de la democracia radical elaborada desde esta perspectiva. La democracia contemporánea, tal como la concibe Mouffe, es lo que des-

${ }^{23}$ Laclau y Mouffe, Hegemony, 1985, pp. 122-127. cribe propiamente la transformación ética y política que produjo el advenimiento de la modernidad. Con la modernidad los fundamentos de la legitimidad política basados en la autoridad de personas específicas -la figura del "príncipe"-, o en la apelación a otras agencias trascendentes, quedaron desmontados. Citando a Lefort, Mouffe indica que la "disolución de las marcas de certidumbre" que produjo la modernidad se vio traducida, en el plano de lo político, en el vaciamiento simbólico del poder en la sociedad. El lugar del poder queda vacío cuando ninguna narrativa simbólica puede reclamar ser la fuente de la legitimidad de dicho poder. La democracia es, en este razonamiento, el único orden político que reconoce esta indeterminación simbólica del lugar del poder, y que está diseñado para mantener abierta, permanentemente, esa indeterminación. Lefort percibió que la desconexión del poder político con alguna forma de estructura simbólica podía conducir al deseo de cerrar esa brecha por medio del totalitarismo. ${ }^{24}$

\section{Hacia un pluralismo agonístico}

La democracia, entendida de esta forma, no solamente designa una forma de gobierno que institucionaliza el vacío formal del poder politico, sino además tiene como rasgo que es radicalmente pluralista:

Pluralism is radical only to the extent that each term of this plurality of identities finds within itself the principle of its own validity, without this having to be sought in a transcendent or underlying positive ground

${ }^{24}$ Véase Lefort, Democracy, 1988. 


\section{SECUENCIA}

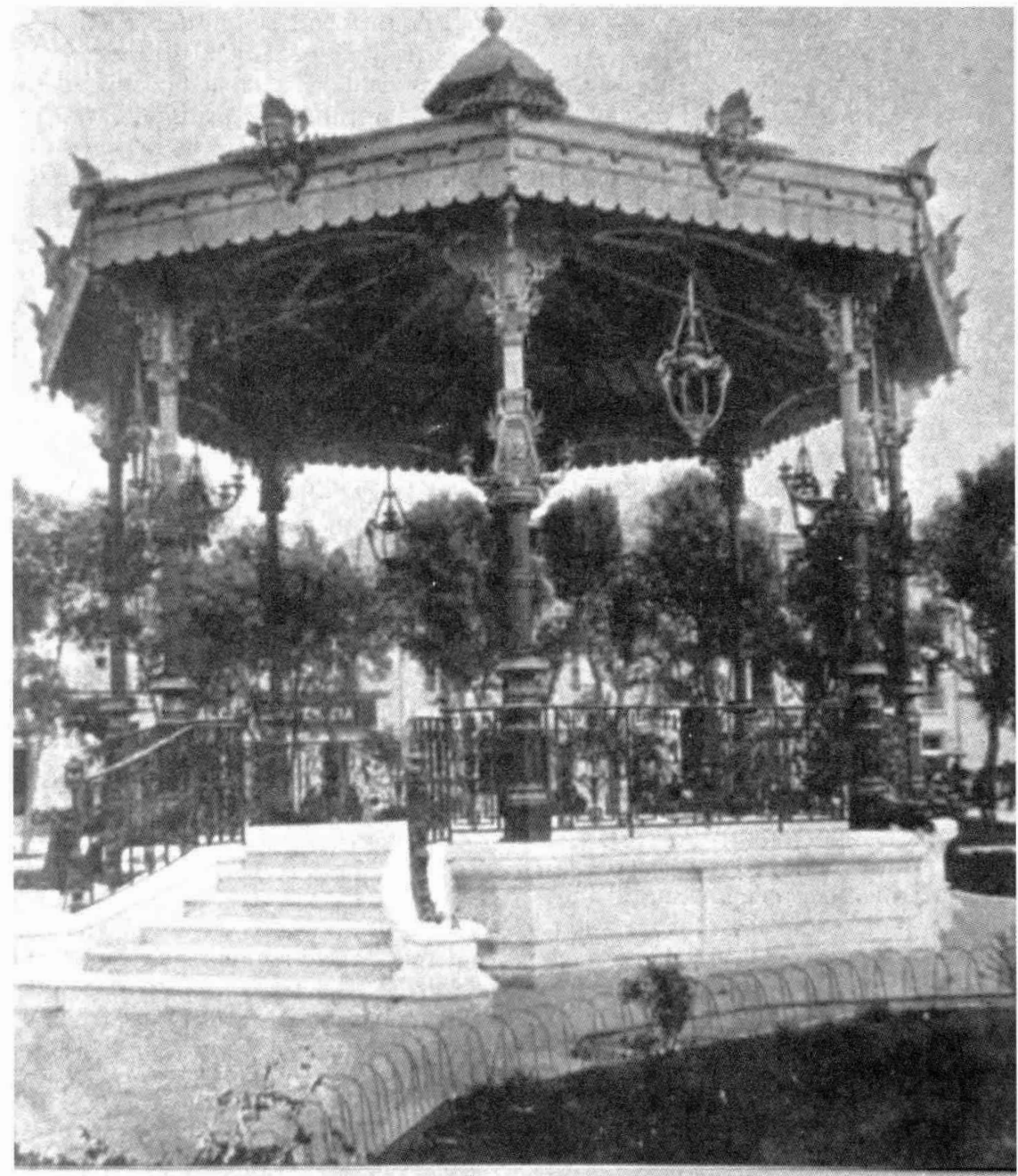

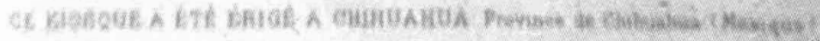


for the hierarchy of meaning of them all and the source and guarantee of their legitimacy. ${ }^{25}$

Las identidades y los sujetos, en el pluralismo radical, carecen de un fundamento que los trascienda; las distribuciones sociales que organizan su convivencia, por lo tanto, son contingentes, históricamente construidas. Además, el pluralismo radical se basa en la noción de que los antagonismos son constitutivos de lo social; por ello, la tensión y el conflicto no son erradicables: tienen que ser asumidos en la sociedad.

El modelo de democracia que defiende Mouffe es el de un "pluralismo agonístico", el cual reconoce el papel constitutivo que desempeña lo político -el conflicto, la confrontación- en la conformación de la multiplicidad de posiciones subjetivas de los miembros de una comunidad política. Sin embargo, la lógica del pluralismo radical implica que ese pluralismo está atravesado por los antagonismos que son constitutivos de las identidades de dicha comunidad política. Para Mouffe, los antagonismos funcionan de acuerdo con la lógica de amigo/enemigo, ${ }^{26}$ por lo que el encuentro de dos posturas anta-

25 "El pluralismo es radical solamente en la medida en que cada término de esta pluralidad de identidades encuentra dentro de sí mismo el principio de su propia validez, sin tener que buscar este principio en un fundamento positivo, trascendente o subyacente, que sea la base del ordenamiento del significado de todas ellas, y la fuente y garantía de su legitimidad" (la traducción es mía). Laclau y Mouffe, Hegemony, 1985 , pp.167.

${ }^{26}$ Una de las fuentes de Mouffe para elaborar la lógica de amigo/enemigo es la noción de lo político de Carl Schmitt. Éste desarrolla esta noción a propósito de sus críticas al parlamentarismo liberal, en el gónicas puede representar el fin del conflicto por medio del aniquilamiento de las partes: la disolución de todo tipo de vínculo social. Por lo tanto, Mouffe señala que la función de las reglas y prácticas democráticas es la de hacer que los antagonismos se conviertan en agonismos: "We can therefore reformulate the problem by saying that envisaged form the perspective of 'agonistic pluralism' the aim of democracy politics is to transform antagonism into agonism." ${ }^{27} \mathrm{El}$ agonismo pluralista implica que los enemigos son vistos como adversarios con quienes se pueden tener diferencias profundas, pero con quienes se comparte el sentimiento de identificación con los principios democráticos.

contexto de la Alemania del periodo de entreguerras. Lo político, tal como lo entiende Schmitt, designa la imposibilidad de erradicar el conflicto, las distinciones entre "amigos y enemigos", de la sociedad y el Estado contemporáneos. Para este autor, los principios liberales, como el diálogo, la publicidad y la neutralidad, antes que contribuir al fortalecimiento del Estado, son determinantes de las inestabilidades y crisis que lo aquejan -como acontecía con la república de Weimar-, justamente porque no alcanzan a entender la naturaleza de lo político. Véase. Schmitt, Concepto, 1998. Un punto relevante de discusión, como señaló uno de los revisores de este artículo, es si efectivamente la noción de lo político de Schmitt puede ser articulada con los principios de la democracia y, en específico, con la democracia radical, tal como la entiende Mouffe. Esta cuestión no puede ser tratada aquí, pero implica revisar internamente la concepción de lo político de esta autora, y el sentido que los antagonismos y los agonismos tienen en su concepción de la democracia.

27 "Podemos entonces reformular el problema diciendo que, visto desde la perspectiva del 'pluralismo agonístico', la finalidad de la política democrática es transformar los antagonismos en agonismos". Mouffe, Democratic, 2000, p. 103. 
DEL AGONISMO A LA DELIBERACIÓN

Las aportaciones provenientes del campo posestructural a la teoría de la democracia parecen estar centradas en el esclarecimiento de las dimensiones ontológicas de este orden político. Desde esta perspectiva, la democracia designa un sistema político que es compatible con la permanente apertura, indeterminación e indecibilidad de toda articulación política. Como se mencionó en la sección anterior, si la existencia de lo social está determinada simultáneamente por la imposibilidad de su completitud perfecta, la democracia permite institucionalizar las reglas para disputar el poder y la configuración de la comunidad política. Las fronteras de ésta, desde una lógica democrática, están permanentemente en condición de ser impugnadas y replanteadas. Sin embargo, mi argumento es que la reflexión deconstructiva no indica cómo "hacer disponibles" las formas de subjetividad democrática en las sociedades actuales. Irónicamente, cuando se pretende superar este límite, se ha de recurrir a una noción deliberativa del proceso político.

\section{El pluralismo agonístico, sus límites $y$ sus implicaciones}

El modelo del pluralismo agonístico propone profundizar el proyecto democrático por medio de la expansión de gramáticas democráticas entre las distintas esferas e identidades de los sujetos que conforman la comunidad política. Este modelo intenta responder a la necesidad de imaginar una comunidad política donde el pluralismo y la diferencia tengan una participación efectiva, sin tener que estar regulados por una concepción mínima de lo político, como en el liberalismo, o por una noción de bien común, como en el republicanismo. ${ }^{28}$ Para ello, una de las principales tareas de la ética democrática es convertir los antagonismos en agonismos: hacer que los otros no sean vistos como enemigos, sino como adversarios políticos.

La teoría democrática planteada de esta forma obliga a hacerse diversas preguntas. Una de ellas: en el planteamiento de Mouffe ¿cómo se concibe el proceso por medio del cual los antagonismos pueden transformarse en agonismos políticos? En términos más concernientes a la realidad de la democracia, también se puede plantear esta interrogante: una vez que existe un escenario que se adecua al modelo del "agonismo pluralista" ¿cómo se concibe la toma de decisiones políticas entre las partes de un conflicto que, no obstante ser adversarios irreconciliables, se apegan a las reglas del juego democrático? El argumento que pretendo defender es que, para responder ambas preguntas, es necesario remitirse a un proceso de entendimiento político. En el primer caso, se trata de crear un terreno común entre dos posturas irreconciliables. Esto puede hacerse por medio de la referencia a un parámetro externo, que podría fungir como mediador entre ambos polos antagónicos; pero entonces el punto es resolver cuáles son las bases para apelar a un parámetro específico. Esto nos remite a la reflexividad de la creación de las reglas de un encuentro, por un lado, y a la necesidad de crear un lenguaje común, por el otro. En ambas situaciones nos vemos en

${ }^{28}$ Véase Mouffe, "Democratic", 1992. 
la necesidad de dar cuenta de los procesos de comunicación que son necesarios para lograr las condiciones de un escenario de mediación democrático.

En el segundo caso tenemos dos salidas. La primera de ellas es seguir un procedimiento imparcial para la toma de decisiones, en el que puedan participar los actores involucrados para hacer valer sus preferencias, ya sea por medio del voto o por medio de su respectiva capacidad de influencia. En esta salida tenemos una forma de proceso político que, como señala Young, ${ }^{29}$ es muy semejante a una concepción pluralista-agregativa de la democracia. Este tipo de modelo en la teoría política no necesariamente contribuye a profundizar la democracia, tal como sería esperado por los teóricos de la democracia radical. La segunda opción es definir un procedimiento de decisión política en el que los adversarios no solamente hagan valer sus intereses, sino que modifiquen sus preferencias y lleguen a un acuerdo a través del intercambio de motivos y razones. Esta alternativa nos coloca dentro del campo de debate de la democracia deliberativa. A su vez, esta opción nos conduce a dos señalamientos más.

En primera instancia, parece que para imaginar un proyecto de democracia radical no es suficiente con atender los aspectos disruptivos de lo político. El pluralismo democrático requiere también de una concepción robusta del proceso comunicativo entre las diferencias políticoculturales. Sin esa dimensión comunicativa, la política asume la forma de un escenario de comperencia sin posibilidad de entendimiento. En segundo término,

29 Young, Inclusion, 2000, p. 51. la elaboración conceptual de dicho proceso comunicativo debe evitar los estándares de unanimidad y racionalismo que caracterizan a la formulación inicial de la democracia deliberativa. Como se verá en la sección siguiente, algunos partidarios de la deliberación tienen en cuenta este segundo punto.

Por otra parte, un giro hacia un replanteamiento de la idea de deliberación pública es perceptible entre autores posestructuralistas. ${ }^{30}$ Norval plantea que la noción de "indecidibilidad", proveniente del campo deconstructivo, posee condiciones que posibilitan pensar en ciertas características de la democracia, como son la responsabilidad, el compromiso, la apertura y la accountability. Para Norval, "la democracia se convierte en una de las formas posibles de dar cuerpo a la experiencia de la indecidibilidad". ${ }^{31}$ Norval plantea que el concepto de "decisión", en su sentido político, tal como lo emplean Laclau y Mouffe, deja sin responder cómo un proceso hegemónico puede conducir a

${ }^{30}$ Para dar un ejemplo más anecdótico que sistemático, Ernesto Laclau, al discutir lo que implica el proceso de representación política para generalizar una formación hegemónica, utiliza una retórica que recuerda a la que emplean los teóricos deliberativos: "Si un sector particular tiene que encarnar las metas universales de la comunidad, la representación es esencialmente inherente al vínculo hegemónico [...] L L tarea de un representante en el Parlamento, por ejemplo, no consiste simplemente en transmitir las aspiraciones de quienes representa; deberá elaborar $u n$ nuevo discurso que convenza a los otros miembros - por ejemplo, argumentando que los intereses de aquellos a quienes representa son compatibles con el interés nacional, y demuai." Laclau, "Identity", 2000, pp. 211-212, la traducción y las cursivas son mías.

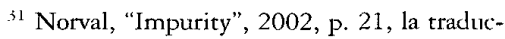
ción es mía. 
una hegemonía democrática. Es decir, Laclau y Mouffe conciben a la decisión como el acto que articula, que funda un orden social, y para el cual no hay un sentido trascendente que le sirva de fundamento. De acuerdo con Norval, la decisión es un acto que se puede presuponer a partir de la experiencia de lo "indecidible", ${ }^{32}$ el cual es la experiencia que atraviesa toda producción de sentido, y que se sitúa en ese espacio entre alternativas y cursos de acción posibles. En un texto, lo "indecidible" se puede reconstruir a partir de las decisiones tomadas, de los caminos recorridos efectivamente. El punto consiste en que la experiencia de lo "indecidible" marca al sujeto (abstracto) de la decisión, lo hace responsable en la medida en que su acto no está resguardado por ninguna garantía. Por ello, Norval señala que los aspectos de responsabilidad y rendición de cuentas que marcan esa experiencia conectan, al menos, de manera indirecta con la posibilidad de la democracia. En otro sentido, Norval aboga por una concepción "atenuada" de la deliberación, que venga a llenar los vacíos abiertos por las versiones posestructurales de lo político. ${ }^{33}$ Esta versión atenuada debe ser entendida como una forma de entendimiento que se actualiza a través de las posibilidades de cooperación, negociación y compromiso en el proceso político. Norval es crítica con el ideal deliberativo de corte haber-

${ }^{32}$ La noción de "indecidibilidad" es original de Jacques Derrida. En aras de seguir el argumento de Norval, sigo aquí la interpretación que ella hace de este término. Sobre el concepto de "indecidibilidad" en el contexto de la discusión acerca de la legalidad y la justicia, véase Derrida, "Force", 1992.

33 Norval, "Democratic", 2000, p. 33. masiano, que pretende un consenso unánime como marca legítima del proceso de diálogo; pero también señala que las nociones de contingencia, hegemonía y antagonismo no proporcionan pistas para emprender la institucionalización y la formación de los procesos democráticos.

Las aportaciones de la vertiente posestructural de la teoría de la democracia no son menores, y muestran que la conformación de identidades y arreglos sociopolíticos proceden a partir de la articulación no fundacional de distintos elementos en formaciones hegemónicas; las cuales, sin un sentido peyorativo, son formaciones que "construyen" la realidad social. Pero esto no es todo. Una de las principales contribuciones de esta orientación es el énfasis que ponen en que tales articulaciones identitarias y hegemónicas están subvertidas por los elementos que dejan fuera de sí para adquirir una consistencia ontológica. La instauración y reproducción de lo social no puede sino renegociar los equilibrios con esas fuerzas que presionan sobre sus límites, buscando reconfigurarlos. La democracia es el sistema que institucionaliza las disputas por la delimitación de la comunidad política y sus sujetos de derechos. Sin embargo, la democracia es también un sistema que se reproduce cotidianamente a partir de acuerdos y decisiones que toman los actores sociales para regular su convivencia. Sobre cómo lograr que tales acuerdos y decisiones sean justos y legítimos, la perspectiva posestructural proporciona poca información. Es por ello que hace falta replantear, con bases no restringidas al consenso, los términos de la deliberación pública. 
ESCENARIOS PARA LA DELIBERACIÓN PÚBLICA: LAS CONTIENDAS ENTRE DISCURSOS EN LA ESFERA PÚBLICA Y LOS PÚBLICOS PARTICIPATIVOS

La crítica posestructuralista de la idea de deliberación pública ha puesto de manifiesto que una conceptualización adecuada de la democracia no puede prescindir de los aspectos polémicos y disruptivos de lo político. Cuando la deliberación pública designa una forma de justificación normativa de las instituciones democráticas, que obliga a las decisiones políticas a estar basadas en estándares de consenso y unanimidad, se crea un marco restringido para la legitimación democrática. Los posestructuralistas, en cambio, proponen concebir a los procesos políticos como procesos que producen y reproducen las articulaciones que dan sentido a lo social, por medio de los conflictos que, constantemente, negocian las fronteras de inclusión y representación política.

Sin embargo, aun esta perspectiva deja sin explicar cómo, en las realidades macro y micro de las sociedades existentes, se pueden concebir los procesos democráticos de una manera más sustantiva que como una lucha entre grupos de interés. Cuando se trata de ir más allá de esclarecer la naturaleza de lo político y de la democracia, las discusiones posestructurales $\mathrm{y}$ deconstructivas han reflexionado poco o, por lo menos, no han intentado teorizar los procesos que conducen a la creación de gramáticas democráticas en la vida social. Estos desafíos han sido encarados por los partidarios de la concepción deliberativa de la democracia. Con estos señalamientos, hay que ser enfáticos respecto a que no se pretende hacer compatibles las aportaciones deliberativas y posestruc- turalistas. La finalidad es mostrar que el planteamiento deliberativo puede expandirse hasta alcanzar los desafíos impuestos por la vía deconstructiva de lo político, y que la concepción deliberativa de la democracia proporciona elementos para entender la construcción legítima de acuerdos en escenarios constituidos por un pluralismo radical.

En esta sección voy a introducir la concepción discursiva de la democracia de John Dryzek ${ }^{34}$ y la noción de "públicos participativos" de Leonardo Avritzer. ${ }^{35}$ La intención de citar la elaboración de Dryzek es enfatizar que una concepción expandida y, al mismo tiempo, compleja de la deliberación pública puede responder las críticas de los autores posestructurales. Las aportaciones de Dryzek tratan de extraer de la idea de esfera pública, desarrollada por Habermas, el potencial crítico de esta noción. Esta concepción es crítica de la restricción del proceso deliberativo a la articulación normativa entre liberalismo y democracia; considera que el proceso deliberativo no debe conducir a un consenso, ni debe estar expuesto en la forma de argumentos racionales, y tiene una concepción del proceso deliberativo en la que el desacuerdo y la disputa son elementos constitutivos de la reflexión colectiva ("contienda entre discursos en la esfera pública"). Por otra parte, las aportaciones de Avritzer, que también establecen con Habermas un diálogo crítico, ilustran la relevancia que tiene una perspectiva deliberativa para entender los procesos de democratización en América Latina. ${ }^{36}$

${ }^{34}$ Dryzek, Deliberative, 2000.

35 Avritzer, Democracy, 2002.

${ }^{36} \mathrm{La}$ aportación de Avritzer puede ser leída de acuerdo con la distinción que realiza Fraser entre "pú- 


\section{SECUENCIG}

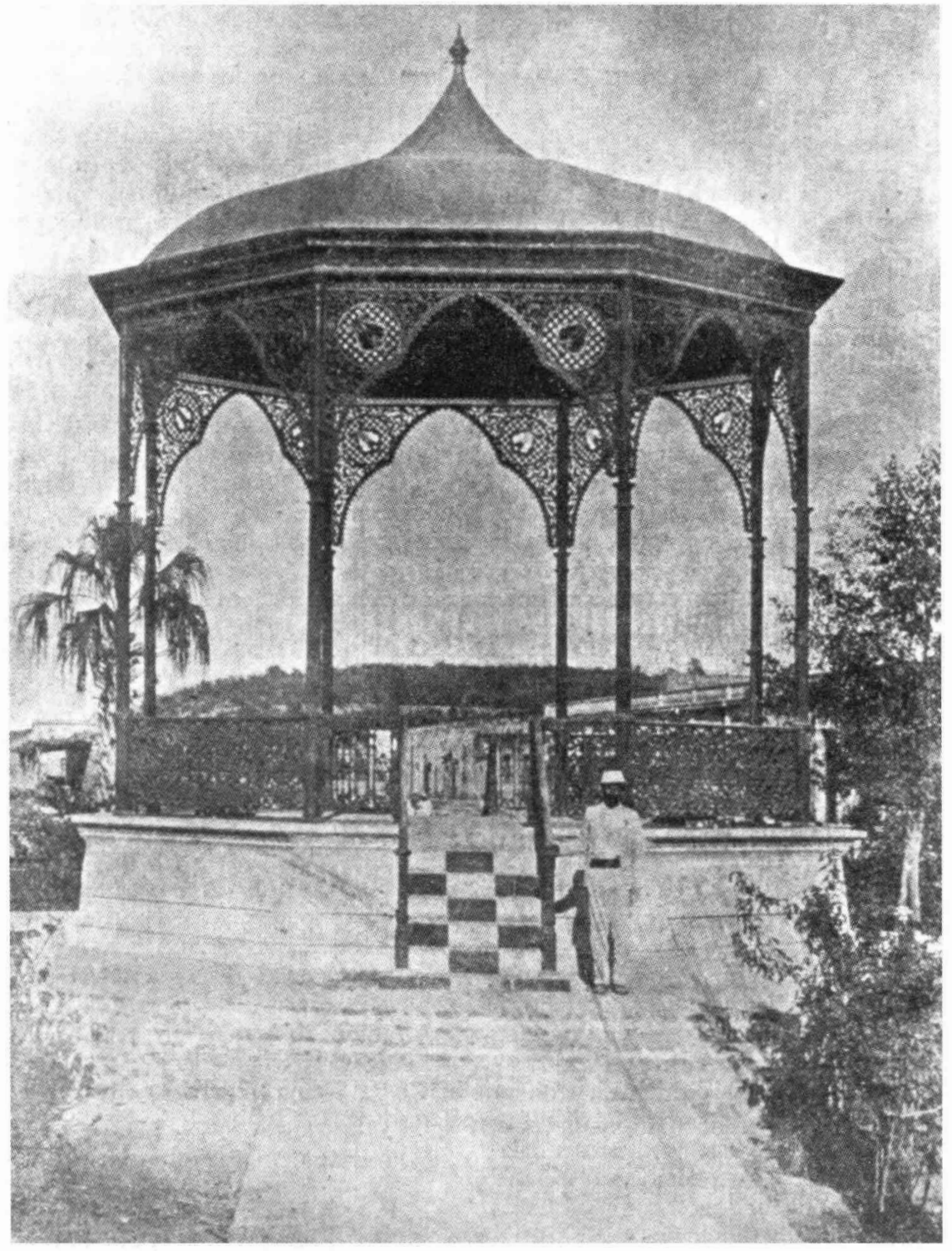

(c) $($ i) (2) 


\section{Democracia discursiva}

Al igual que los autores posestructuralistas, Dryzek es crítico del acomodo que ha encontrado la democracia deliberativa en el pensamiento liberal. Según este autor, la democracia deliberativa, planteada en términos cercanos al liberalismo, se distancia de sus orígenes en la teoría crítica; queda restringida a ser un medio para justificar los derechos liberales; se la institucionaliza por medio de las constituciones para llevarse a cabo en cortes y parlamentos; y se la concibe, también, como un proceso que sirve al fin del diseño constitucional. ${ }^{37}$ En contraposición, Dryzek suscribe una vertiente que busca continuar la tradición de la teoría crítica. Su propuesta es denominar a esta vertiente "democracia discursiva", ${ }^{8}$ cuyo fin es promover la autenticidad democrática, pretende ser pluralista, reflexiva, transnacional, ecológica y dinámica, y crítica de la apropiación liberal de la deliberación pública. ${ }^{39}$

blicos débiles" y "públicos fuertes". Frases, "Rethinking", 1992. Los públicos "débiles" son instancias de participación, deliberación y formación de la opinión pública que, sin embargo, carecen de poder de decisión política. Los públicos "fuertes", como los parlamentos y los "públicos participativos" de Avritzer, en cambio, además de ser esferas institucionales de deliberación, tienen también la capacidad de generar decisiones vinculantes. Agradezco a uno de los revisores de este artículo este señalamiento.

${ }^{37}$ Dryzek, Deliberative, 2000, pp.9-20.

${ }^{38}$ Ibid., p. VII; véase también, Dryzek, Discursize, 1990.

${ }^{39}$ Dice Dryzek: "Argumentaré entonces que la democracia discursiva debe ser pluralista en el sentido de adherirse a la necesidad de que exista comunicación a través de las diferencias, sin tener que borrar tales diferencias; reflexiva como orientación crítica hacia
Dryzek considera que el concepto de democracia discursiva está comprometido con la autenticidad de la democracia. Para lograr dicha autenticidad, dicho autor señala que es preciso que los procesos intersubjetivos de comunicación promuevan procesos no coercitivos de reflexión acerca de las preferencias. ${ }^{40}$ De aquí se sigue que la autenticidad democrática se alcanza cuando las decisiones colectivas se toman con base en la influencia de ese proceso de deliberación. ${ }^{41}$ Un primer aspecto a destacar es que, puesta de esta forma, las condiciones para la deliberación no se establecen a priori como una serie de principios que deben ser cumplidos. De esta manera no se asume que el producto deliberativo debe ser un consenso unánime entre las partes; de igual modo, también deja abierta la posibilidad de que la deliberación se realice por medios retóricos distintos a los de la argumentación racional. En las ocasiones en las que la toma de decisiones políticas se lleva a cabo en escenarios de interacción cara a cara, los procesos de deliberación deben llegar a "acuerdos razonados", a los que las partes pueden llegar por razones distintas. ${ }^{42}$

En segundo lugar, para Dryzek la autenticidad de la democracia no se consigue a través de diálogos racionales y desapasionados en los parlamentos. Dicha

las tradiciones establecidas; transnacional en su capacidad de extenderse a través de las fronteras estatales, hacia escenarios en los que no hay un marco constitucional; ecológica en términos de su apertura a la comunicación con la naturaleza; y dinámica en su apertura hacia las siempre cambiantes restricciones y oportunidades para la democratización." Dryzek, Deliberative, 2000, p. 3. La traducción es mía.
40 Ibid., p. 2.
${ }^{41}$ Ibid.
42 Ibid., p. 47. 
autenticidad se produce a partir de procesos deliberativos que proceden de la esfera pública -en esto su argumentación se deriva de Habermas. También considera propiamente al proceso democrático como una "contienda de discursos en la esfera pública" ("Contest of Discourses in the Public Sphere"). Los discursos son entendidos como campos simbólicos que estructuran el modo en que los individuos se relacionan entre sí y con sus realidades. Cuando los distintos discursos fluyen en los espacios comunicativos de la esfera pública pueden acontecer desacuerdos acerca de distintos temas comunes y políticos; entonces, el proceso deliberativo se desarrolla como un proceso de "contienda entre discursos". Pero esta contienda se resuelve, no a partir de un consenso racional, ni por medio del voto de individuos particulares, sino a partir de procesos donde las partes exponen colectivamente sus preferencias y llegan a acuerdos reflexivos.

Con estos planteamientos, la concepción deliberativa de la democracia adquiete un nuevo perfil. No se trata meramente de un ideal de justificación política que tiene problemas para acomodar en su interior el desacuerdo y la polémica, sino de un modelo que pone en el centro de los procesos de democratización una concepción comunicativa de la construcción de la legitimidad política. Una concepción comunicativa que cruza las diferencias y respeta los desacuerdos, en aras de alcanzar decisiones vinculantes. Puesto de este modo, resulta que el adversario de la profundización democrática no es la noción deliberativa, como podrían señalar autores como Chantal Mouffe, sino una versión restringida del proceso deliberativo.

Los replanteamientos de la democracia deliberativa proporcionan elementos para imaginar cómo llevar a cabo la profundización de la democracia en el mundo actual. ${ }^{43}$ Para tal efecto, se puede mencionar que Dryzek no solamente distingue entre procesos de deliberación en escenarios microsociales y procesos de deliberación más amplios que transcurren en la esfera pública, sino que discute las implicaciones de su teoría para entender las relaciones sociedad civil-Estado, la política internacional, el pluralismo cultural y los desafíos ecológicos. Sin embargo, para concluir esta sección, voy a referirme a una propuesta concreta, elaborada desde la concepción deliberativa de la democracia, para interpretar y promover los procesos de democratización en América Latina. Se trata de la noción de "públicos participativos", desarrollada por Leonardo Avritzer.

\section{Públicos participativos en América Latina}

La noción de "públicos participativos" representa una contribución para repensar los procesos de democratización en América Latina. ${ }^{44}$ En los países latinoamericanos, la democracia enfrenta problemas de consolidación que se originan, de acuerdo con Avritzer, en un proceso hístórico de hibridación entre las instituciones polí-

${ }^{43}$ La elaboración de Dryzek no es la única que se puede citar como un fuerte argumento a favor de la democracia deliberativa en las sociedades complejas. Bohman, Public, 1996, y Young, Inclusion, 2000, han realizado también contribuciones al respecto.

${ }^{44}$ Propuestas que adoptan una lógica semejante a la de los públicos participativos han sido elaboradas también por otros autores. Véanse, al respecto, Cohen y Rogers, Associations, 1995, y Fung y Wrigth, Deepening, 2003. 
ticas occidentales, como el liberalismo y la democracia, y las tradiciones culturales latinoamericanas preexistentes, incluida la influencia colonial ibérica. ${ }^{45}$

La difusión de prácticas democráticas, tanto en la sociedad política como en la sociedad civil, en este escenario hibrido, ha estado limitada por la implantación de instituciones con una racionalidad administrativa poco vinculada a las tradiciones culturales del contexto en que se insertaron; además, por el comportamiento de las elites, que constantemente han perseguido sus objetivos por vías no democráticas, en escenarios institucionales democráticos; y por una concepción homogenizada de la acción colectiva, basada en el lugar privilegiado que se le ha dado a los actores populares en la política latinoamericana. Avritzer advierte que, en este escenario, no fue posible establecer condiciones básicas para un espacio público democrático.

En ese sentido, nunca llegó a establecerse una distinción nítida entre los ámbitos de lo privado y lo público; tampoco se desarrollaron formas asociativas heterogéneas, que habitaran los espacios públicos; y, por otra parte, no fue posible desligar las movilizaciones populares de demandas particularistas establecidas en términos de intereses de clase. De esta forma, en la política latinoamericana han prevalecido dos lógicas: por un lado, la organización de las instituciones estatales, para servir a los intereses de las elites y, en su caso, a los de las masas; y, por el otro, la reproducción sistemática de desigualdades deliberativas de los individuos ante, y en el interior de, las instituciones políticas.

${ }^{45}$ Avritzer, Democracy, 2002, pp. 69-70.
La teoría política y, en específico, las teorías de la democracia, según este autor, también se han visto en problemas para ofrecer interpretaciones que ayuden a pensar cómo robustecer los espacios democráticos. Tales teorizaciones han fallado en apreciar la importancia de la apertura de los espacios públicos en América Latina para los procesos de democratización. De acuerdo con Avritzer, las teorías convencionales de la democracia restringen el ámbito de lo político a las esferas gubernamentales, favorecen la concentración de las decisiones pólíticas en las elites gobernantes, y son recelosas de las movilizaciones colectivas -pues temen que las "masas" sobrepasen la capacidad de las instituciones políticas de gestionar sus demandas. ${ }^{46}$ Avritzer también crítica los enfoques sobre las transiciones a la democracia en la región. Los teóricos de las transiciones -indica- se preocupan principalmente por la capacidad de las elites para restaurar la competencia política. ${ }^{17}$ Sin embargo, las elites gobernantes latinoamericanas se han caracterizado por su profundo desdén a los derechos humanos, a la autonomía organizativa de la sociedad civil o al efectivo imperio de la ley; inclusive, se muestran proclives a no respetar: los resultados de los procesos electorales. Por eso, dice este autor, es necesaria una conceptualización que vaya más allá de la restauración de la competencia política a manos de las minorías en el poder.

46 Al respecto véanse Schumpeter, Capitalism, 1947; Downs, Economic, 1957; Huntington, Political, 1969, y Third, 1991, y Sartori, Theory, 1987, vol. I.

47 Véanse, por ejemplo, O'Donnell y Schmitter, Transitions, 1986, vol. II, y Linz y Stepan, Problems, 1996. 
La argumentación de Avritzer señala que la apertura de los espacios públicos en América Latina ha contribuido a crear una nueva cultura de la democracia. Para ello se refiere a los movimientos sociales que surgieron entre las décadas de los años setenta y ochenta: movimientos a favor de los derechos humanos en Brasil y Argentina; movimientos urbano-populares en Brasil y México; y campañas para monitorear el desempeño de la sociedad política en Brasil y México. Sin embargo, la parte central de su argumento se refiere a las innovaciones introducidas por instituciones como los Presupuestos Participativos -implementados en Porto Alegre y Belo Horizonte-, en Brasil, y el Instituto Federal Electoral, en México. En ambos casos, se trata de instituciones diseñadas para servir de mediadoras entre la ciudadanía y los actores políticos, que son producto de las demandas ciudadanas de restaurar los principios democráticos, ante la resistencia de los propios partidos políticos y grupos de poder en el gobierno. Estas innovaciones, llamadas "públicos participativos", son instituciones administrativamente complejas, que sirven de espacios para la toma de decisiones políticas con base en la participación ciudadana y la deliberación pública. Para Avritzer, la formación de los públicos participativos involucra cuatro elementos. ${ }^{48}$ en primer lugar, la formación, en el espacio público, de mecanismos de deliberación cara a cara, libre expresión y asociación, por medio de los cuales se discuten y problematizan temas específicos; en segundo, se encuentra la idea de que los movimientos sociales y las asociaciones voluntarias producen controver-

${ }^{48}$ Linz y Stepan, Problems, 1996. sias por medio de la introducción de prácticas alternativas en el espacio público; en tercer lugar, los públicos participativos preservan un espacio de complejidad administrativa y, al mismo tiempo, desafían el acceso exclusivo de los especialistas a los sitios donde se toman las decisiones; por último, los "públicos participativos" articulan las deliberaciones con la intención de encontrar formatos institucionales capaces de llevar a cabo, en el plano de las políticas públicas, los temas discutidos públicamente.

Asimismo, constituyen una propuesta específica de diseño institucional que, además, introduce una nueva concepción de los procesos de decisión política e implementación administrativa. Desde este enfoque, la instalación de espacios deliberativos, entre la formación de la opinión pública y la implementación administrativa, ofrece la posibilidad de hacer partícipes a los individuos, en condiciones de igualdad y equidad, en la toma de decisiones vinculantes. Como señala Avritzer:

only by giving public processes of communication and deliberation an institutional dimension can we transform public sphere theory from a theory of the possibility of participatory democracy into a truly democratic and deliberative theory."

Esta propuesta, para las sociedades latinoamericanas, lleva aneja la posibilidad

49 "Solamente dándole a los procesos de comunicación pública y deliberación una dimensión institucional podremos hacer que la teoría de la esfera pública, de ser una teoría acerca de las posibilidades de la democracia participativa, sea una verdadera teoría de la democracia y la deliberación." Ibid., p. 52. La traducción es mía. 
de abrir nuevos espacios institucionales de supervisión y control sobre los procesos políticos.

La democracia deliberativa, como se ha visto hasta aquí, ha producido un campo de intenso debate. En este caso, las propuestas de Dryzek y de Avrizter permiten responder las objeciones posestructuralistas: un enfoque deliberativo no necesariamente tiene problemas con el pluralismo y el disenso. La contienda de los discursos en la esfera pública designa un proceso que asume los conflictos fluctuantes que se producen en la sociedad; adicionalmente, concebir a la deliberación como un proceso conjunto de cooperación y reflexión en torno a temas polémicos, lleva los acuerdos políticos más allá de la idealización del consenso. Por otra parte, la perspectiva deliberativa proporciona referentes concretos para vincular los procesos deliberativos con la complejidad institucional y la profundización democrática. Los "públicos participativos" cumplen con esta función, y constituyen foros deliberativos en contacto estrecho con la sociedad civil y en relación crítica con el Estado. Estos foros representan alternativas viables para impulsar la participación ciudadana, incrementar el control social sobre los procesos políticos $\mathrm{y}$, pongámoslo de esta forma, para fungit como instancias de transformación de los antagonismos en agonismos democráticos.

\section{CONCLUSIONES}

Una de las tareas más importantes para la teoría política y la teoría de la democracia, hoy en día, es proporcionar argumentos normativamente defendibles que sean, a la vez, susceptibles de ser transformados en principios institucionales y en parámetros regulativos de la vida política en la sociedad contemporánea. En este trabajo se han discutido las críticas que la teoría política proveniente del campo posestructuralista/deconstructivo hace a la idea de deliberación pública. De la misma manera, a partir de una revisión del planteamiento posestructural y, más concretamente, del modelo del "pluralismo agonístico", se han puesto de manifiesto los límites de una concepción del proceso democrático basada en el solo poder disruptivo de lo político. La lectura de la aproximación posestructural ha servido, en este trabajo, para reintroducir el planteamiento deliberativo. A partir de una concepción expandida de la deliberación pública, que entiende la legitimidad democrática como el producto de acuerdos razonados, no consensuales, derivados de las contiendas entre discursos en la esfera pública, se ha argumentado a favor de una concepción comunicativa del proceso democrático. Se ha mostrado, de igual manera, específicamente para el caso latinoamericano, que la perspectiva deliberativa ha dado lugar a nuevas interpretaciones de los procesos de democratización, y ha sugerido arreglos institucionales innovadores para promover la deliberación pública. La intención de este trabajo ha sido contribuir, si bien en un plano un tanto abstracto, a la apropiación que se desarrolla actualmente en México y otros países de la región latinoamericana, de la idea de la democracia deliberativa. Esta idea, como se ha intentado mostrar, permite recuperar las experiencias de múltiples experimentos innovadores en materia de participación ciudadana y deliberación pública; más aún, invita a promover la difusión y replicación de tales experiencias. 


\section{SECUENCIA}

FINDICION DE SINALOA-NAZATLAN.

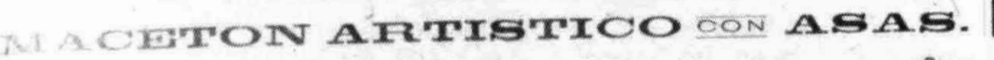

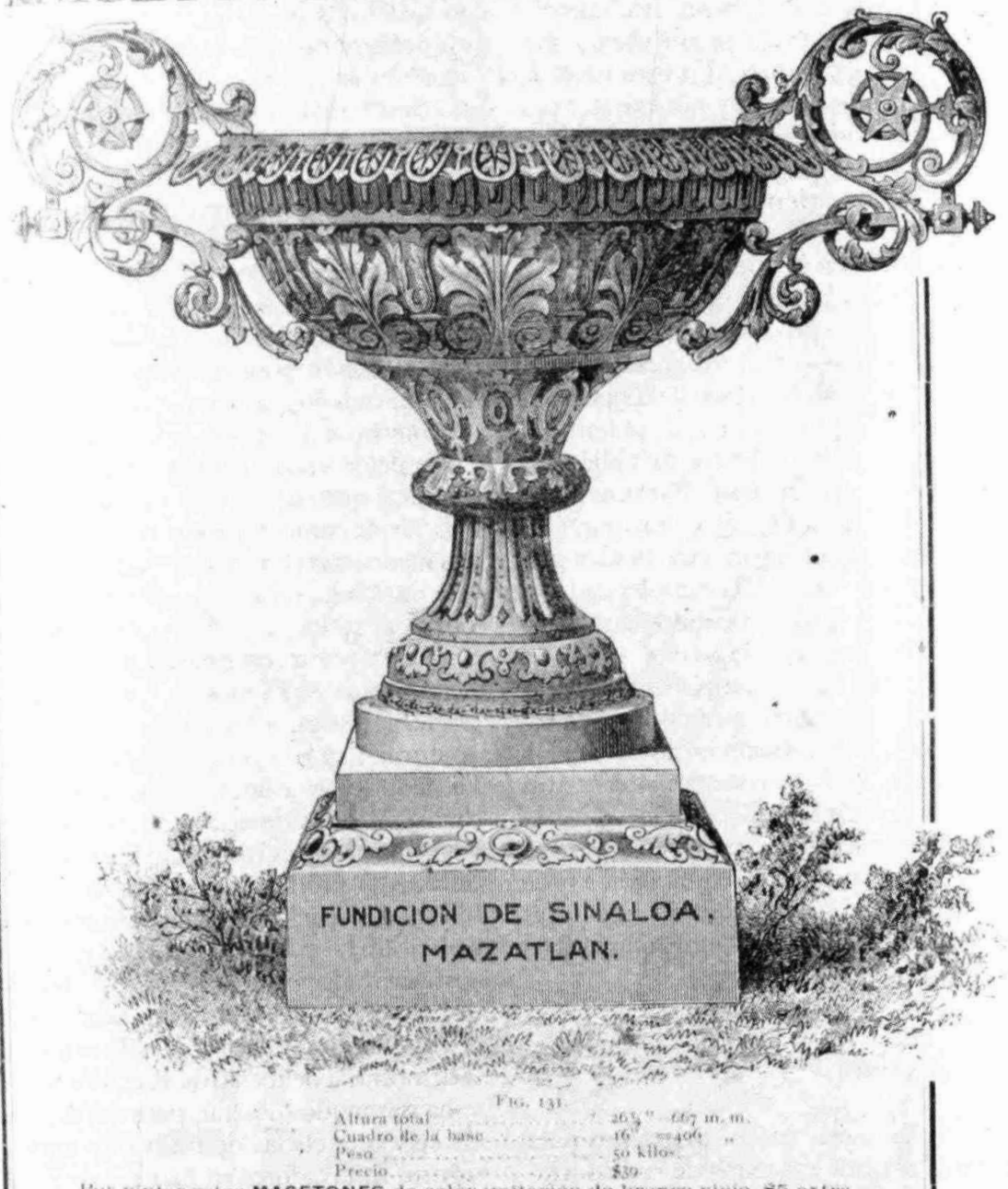




\section{BIBLIOGRAFÍA}

-Avritzer, Leonardo, Democracy and the Public Space in Latin America, Princeton University Press, Princeton, 2002.

-Bohman, James, Public Deliberation: Pluralism, Complexity and Democracy, MTT Press, Cambridge, 1996.

(ed.), Deliberative Democracy: Essays on Reason and Politics, MTT Press, Cambridge, 1999.

-Cohen, Joshua, "Deliberation and Democratic Legitimacy" en David Estlund (ed.), Democracy: Philosophical Readings, Blackwell Publishing, Oxford, 2002, pp. 87-106.

- , "Democracia y libertad" en Jon Elster (comp.), La democracia deliberativa, Gedisa, España, 2001, pp. 235-288.

—_, "Procedure and Substance in Deliberative Democracy" en Thomas Christiano (ed.), Philosophy and Democracy, Oxford University Press, Oxford, 2003, pp. 17-38.

-Cohen, Joshua y Joel Rogers, Associations and Democracy, Verso, Londres, 1995.

-Derrida, Jacques, "Force of Law: The Mystical Foundation of Authority" en Drucilla Cornell, Michel Rosenfeld y David Gary Carlson (eds.), Deconstruction and the Possibility of Justice, Rourledge, Londres y Nueva York, 1992, pp. 3-66.

-Downs, Anthony, An Economic Theory of Democracy, University of New York Press, Nueva York, 1957.

-Dryzek, John, Discursive Democracy: Politics, Police, and Political Science, Cambridge University Press, Cambridge, 1990.

- Deliberative Democracy and Beyond: Liberals, Critics, Contestations, Oxford University Press, Oxford, 2000.

-Elster, Jon (ed.), La demacracia deliberativa, Gedisa, España, 2001.

- "The Market and the Forum: Three Varieries of Political Theory" en Thomas Christiano (ed.), Philosophy and Democracy,
Oxford University Press, Oxford, 2003, pp. 138-158.

-Fishkin, James y Peter Laslett (eds.), Dehating Deliberative Democracy, Blackwell Publishing, Oxford, 2003.

-Fraser, Nancy, "Rethinking the Public Sphere: A Contribution to the Critique of Actually Existing Democracy" en Craig Calhoun (ed.), Habermas and the Public Sphere, Massachusetts Institute of Technology, Cambridge, 1992, pp. 109-141.

-Fung, Archon y Eric Olin Wright (eds.), Deepening Democracy: Institutional Innovations in Empowered Participatory Governance, Verso, Londres, 2003.

-Habermas, Jürgen, Teoría de la acción comunicativa, Taurus, España, 1999, 2 vols. , "Tres modelos normativos de democracia" en Jürgen Habermas, La inclusión del otro. Estudios de teoría política, Paidós, España, 1999, pp. 231 -246. España, 2001.

-, Facticidad y validez, Trotta, 4a. ed.,

-Howarth, David, Aletta J. Norval y Yannis Stavrakakis (eds.), Discourse Theory and Political Analysis, Manchester University Press, Manchester, 2000.

-Huntington, Samuel, Political Order in Changing Societies, Yale University Press, New Heaven, 1969.

- The Third Wave: Democratization in the Late Twentieth Century, University of Oklahoma Press, Norman, 1991

-Kymlicka, Will, Contemporary Political Pbilosophy, Oxford University Press, Oxford, 2002.

-Laclau, Ernesto, "New Reflections on the Revolution of Our Time" en Ernesto Laclau, New Reflections on the Revolution of Our Time, Verso, Londres, 1990, pp. 3-85.

-, "Deconstrucción, pragmatismo, hegemonía" en Chantal Mouffe (comp.), Deconstrucción y pragmatismo, Paidós, Buenos Aires, 1998, pp. 97-136 (Espacios del Saber, 4). 
, "Identity and Hegemony: The Role of Universality in the Constitution of Political Logics" en Judith Butler, Ernesto Laclau y Slavoj Zižek (eds.), Contingency, Hegemony and Universality, Verso, Londres, 2000, pp. 44-90.

-Laclau, Ernesto y Chantal Mouffe, Hegemoony and Socialist Strategy: Towards a Radical Democratic Politics, Verso, Londres, 1985.

-Lefort, Claude, Democracy and Political Theory, Oxford University Press, Oxford, 1988.

-Linz, Juan y Alfred Stepan, Problems of Democratic Transition and Consolidation, John Hopkins University Press, Baltimore, 1996.

-Metapolititica, vol. 4, abril-junio de 2000.

-Mouffe, Chantal, "Democratic Citizenship and the Political Communtiy" en Chantal Mouffe (ed.), Dimensions of Radical Democracy, Verso, Londres, 1992, pp. 225-239. ,El retorno de lo político, Paidós, Barcelona, 1999 (Estado y Sociedad, 69). Londres, 2000. , The Democratic Paradox, Verso,

-Norval, Aletta J., "Democratic Decisions and the Question of Universality: Rethinking
Recent Approaches", Essex Papers in Politics and Government, Department of Government/University of Essex, núm. 151, 2000, Colchester. -, "The Impurity of Politics: Deconstructive Interventions", Essex Pafurs in Politics and Government. SubSeries in Ideology and Discourse Analysis, Department of Government/ University of Essex, núm. 18, 2002, Colchester.

-O'Donnell, Guillermo, y Phillip Schmitter (eds.), Transitions from Authoritarian Rule: Latin America, John Hopkins University Press, Baltimore, 1986 , vol. II.

-Rawls, John, Political Liberalism, Columbia University Press, Nueva York, 1996.

-Sartori, Giovanni, The Theory of Democracy Revisited, Chatham House Publishers, Chatham, 1987.

-Schmitt, Carl, El concepto de lo político, Alianza Editorial, Madrid, 1998.

-Schumpeter, Joseph, Capitalism, Socialism and Democracy, University of New York, Nueva York, 1947.

-Young, Iris Marion, Inclusion and Demorrary, Oxford University Press, Oxford, 2000. 